\title{
The regulation of the expression and activation of the essential ATF1 transcription factor in the mouse preimplantation embryo
}

\author{
$X \mathrm{~L}$ Jin and C O'Neill \\ Sydney Medical School, Kolling Institute for Medical Research, Centre for Developmental and Regenerative \\ Medicine, University of Sydney, Sydney, New South Wales 2065, Australia \\ Correspondence should be addressed to C O’Neill; Email: chris.oneill@sydney.edu.au
}

\begin{abstract}
The co-expression of the CREB and ATF1 transcription factors is required for the development of preimplantation embryos. Embryotropin-mediated, calcium/calmodulin-dependent signalling activates CREB-induced transcription in the two-cell embryo, but the regulation of ATF1 in the embryo is not known. This study demonstrates that ATF1 begins to accumulate within both pronuclei of the mouse zygote by $20 \mathrm{~h}$ post-human chorionic gonadotrophin. This did not require new transcription (not blocked by $\alpha$-amanitin), but was dependent upon protein synthesis (blocked by puromycin) and the activity of P38 MAP kinase. ATF1 becomes an active transcription factor upon being phosphorylated. A marked accumulation of phosphorylated ATF1 was evident in two-cell embryos and this persisted in subsequent stages of development. This phosphorylation was enhanced by the actions of autocrine embryotropic mediators (including Paf) and required the mutual actions of P38 MAP kinase and calmodulin-dependent pathways for maximum levels of phosphorylation. The combined inhibition of these two pathways blocked embryonic genome activation (EGA) and caused embryos to enter a developmental block at the two-cell stage. The members of the CREB family of transcription factors can generate one of the most diverse transcriptomes of any transcription factor. The demonstration of the presence of activated CREB and ATF1 within the embryonic nucleus at the time of EGA places these transcription factors as priority targets as key regulators of EGA.
\end{abstract}

Reproduction (2014) 148 147-157

\section{Introduction}

The members of the cAMP response element-binding protein (CREB) family of bZIP transcription factors activate one of the most extensive transcriptomes known in mammals. The family consists of more than 20 members with CREB (cAMP-dependent transcription factor) or activating transcriptional factor (ATF1), and cAMP-responsive element modulatory protein (CREM) being the major members of this family. These transcription factors are characterised by their activation upon their phosphorylation. CREB is activated upon phosphorylation of serine ${ }^{133}$ (Gonzalez \& Montminy 1989, Chrivia et al. 1993), which corresponds to serine ${ }^{63}$ of ATF1 and serine ${ }^{117}$ of CREM (Masson et al. 1993). Phosphorylation occurs in response to many extracellular stimuli, and differential phosphorylation of various members of the family may occur depending on the nature of the stimulus. The effects of phosphorylation on the activation of CREB are best understood. CREB phosphorylation does not alter its capacity to bind DNA (Hagiwara et al. 1993), but it does enhance the interaction of its KID domain with the KIX domain within its co-activators, such as CREB-binding protein
(CREBBP)/p300, and thus serves to recruit co-activators to the CRE promoter (Kwok et al. 1994, Parker et al. 1996). The recruitment of transcriptional co-activators mediates CREB-stimulated activation of target genes through its association with RNA polymerase II complexes (Kee et al. 1996) and intrinsic histone acetyltransferase activities (Korzus et al. 1998). CREB family transcription factors act as dimers and can both homodimerise and partner with other members of the family to form heterodimers.

Creb and Atf1 (but not Crem) transcripts are present in mouse oocytes and preimplantation embryos (Jin \& $\mathrm{O}^{\prime}$ Neill 2007, 2010). Both Creb ${ }^{-1-}$ and $A t f 1^{-1-}$ mouse embryos are viable, but compound $\mathrm{Creb}^{-/-} / \mathrm{Atf1} 1^{-1-}$ double-knockout mutant embryos die before implantation, showing ATF1 and CREB have essential but mutually compensatory functions (Bleckmann et al. 2002). CREB protein is present in cytoplasm and nuclei, while ATF1 is predominately localised in the nuclei of the late zygote to blastocyst stages (Jin \& O'Neill 2010). An autocrine embryotropin (Paf) induces the expression, phosphorylation and nuclear accumulation of CREB in two-cell embryos. This action was independent of CAMP 
but depends on calcium, calmodulin and calmodulindependent protein kinase activities (Jin \& O'Neill 2007, 2010). Paf elevates the transcription of two canonical CREB-family response genes, $\mathrm{BCl} 2$ and $\mathrm{Fos}$, in the mouse two-cell embryo. This $\alpha$-amanitin-sensitive transcription is dependent upon the action of $\mathrm{Ca}^{++} / 1$-o-phosphatidylinositol-3-phosphate kinase signalling pathways (Jin \& O'Neill 2011).

The aim of the current study was to examine the regulation of ATF1 nuclear localisation and phosphorylation in the early preimplantation embryo. We found that ATF1 nuclear localisation first occurred mid-way through zygotic maturation, and this was dependent upon the activity of P38 MAP kinase. Phosphorylation of ATF1 was apparent by the two-cell stage and required the activities of the P38 MAP kinase- and calmodulindependent signal transduction pathways. Blocking P38 MAP kinase alone had only limited effects on embryo development, but the combined effects of blocking P38 MAP kinase and calmodulin created a two-cell block to development. The study points to critical roles for the P38 MAP kinase and calmodulin pathways in activation of a critical transcription factor in the development of early embryo.

\section{Materials and methods}

\section{Animals}

The use of animals was in accordance with the Australian Code of Practice for the Care and Use of Animals for Scientific Purposes and was approved by the Institutional Animal Care and Ethics Committee. Hybrid (C57BL/6 X CBA/He) mice were used in experiments. Animals were housed and bred in the Gore Hill Research Laboratory, St Leonards, NSW, Australia. All animals were under $12 \mathrm{~h}$ light: $12 \mathrm{~h}$ darkness cycle and had access to food and water ad libitum. Six-week-old females were superovulated with an i.p. injection of $5 \mathrm{IU}$ equine chorionic gonadotrophin (Folligon, Intervet International, Boxmeer, The Netherlands) followed $48 \mathrm{~h}$ later by $5 \mathrm{IU}$ human chorionic gonadotrophin (hCG, Chorulon, Intervet). Females were paired with males of proven fertility. Pregnancy was confirmed by the presence of a copulation plug the following morning (day 1 ). The age of embryos is defined by the period of time since the ovulatory injection of hCG (h post-hCG).

\section{Mouse embryo collection and culture}

Cumulus masses were collected from the reproductive tract 14-22 $\mathrm{h}$ post-hCG in HEPES-buffered modified human tubal fluid medium (HEPES-HTF). Zygotes were freed from their cumulus cells by brief exposure to $300 \mathrm{IU}$ hyaluronidase (Sigma Chemical Company) and cultured in human tubal fluid medium supplemented with glutamine and EDTA (GE-HTF) (O'Neill 1997). All components of the media were tissue culture grade (Sigma) and contained $3 \mathrm{mg} \mathrm{BSA} / \mathrm{ml}$ (Sigma). The embryos were cultured individually (one embryo in $10 \mu \mathrm{l}$ volumes) or communally (ten embryos in $10 \mu$ volumes) in 60-well tissue culture plate (LUX 5260, Nunc, Naperville, IL, USA) overlaid by $\sim 2 \mathrm{~mm}$ of heavy paraffin oil (Sigma). Cultures were incubated at $37^{\circ} \mathrm{C}$ in $5 \% \mathrm{CO}_{2}$ for the periods indicated for individual experiments. The maturation of zygotes was staged according to standard protocols (Adenot et al. 1997) with PN1 being the least and PN5 being the most mature stages before syngamy.

\section{Pharmacological agents and treatments}

1-o-alkyl-2-acetyl-sn-glycero-3-phosphocholine (Paf; Sigma) was prepared as previously described (Collier et al. 1990). 1,2-bis(2-aminophenoxy)ethane- $N, N, N, N$-tetraacetic acid tetrakis (acetoxymethyl ester) (BAPTA-AM) (Sigma), SB203580 (4-(4-fluorophenyl)-2-(4-methylsulphonylphenyl)-5-(4-pyridyl) $1 \mathrm{H}$-imidazole) (Calbiochem, Sydney, NSW, Australia), LY294002 (2-(4-morpholinyl)-8-phenyl-4H-1-benzopyran4-one) (Calbiochem), PD98059 (2'-amino-3'-methoxyflavone) (Sigma), genistein (4',5,7-trihydroxyisoflavone) (Calbiochem) and staurosporine (Calbiochem) were prepared as 2000-fold concentrated stock in dimethyl sulphoxide (DMSO) (Sigma) and on day of use diluted to maximum working concentrations of $10 \mu \mathrm{M}$ BAPTA-AM, $50 \mu \mathrm{M}$ PD98059, $25 \mathrm{nM}$ staurosporine, $10 \mu \mathrm{M} \mathrm{SB} 203580,10 \mu \mathrm{M} \mathrm{LY} 294002$, and $15 \mu \mathrm{M}$ genistein with GE-HTF medium. Some were serially diluted into the lower concentrations while maintaining the concentration of DMSO. A concentration of DMSO $(0.05 \%, \mathrm{v} / \mathrm{v})$ was used for each agent and control media also had this same amount as that of DMSO. Puromycin (Sigma), PKA inhibitor 14-22 amide (Myr-GRTGRRNAI-NH2; Merck), W-7 (N-(6-aminohexyl)5-chloro-1-naphthalenesulphonamide, $\mathrm{HCl}$; Merck) and $\alpha$-amanitin (Sigma) were prepared at working concentrations by dissolving directly in GE-HTF on day of use.

Zygotes were recovered $18 \mathrm{~h}$ post-hCG in minimal volume and subjected to three treatment periods according to the experimental design: 4, 24, and $96 \mathrm{~h}$.

Inhibitor treatments were as follows: i) control media alone; (Lu et al. 2004) ii) $18 \mu \mathrm{M}$ puromycin; iii) $26 \mu \mathrm{M} \alpha$-amanitin; iv) 1-25 nM staurosporine; v) 0.6-10 $\mu \mathrm{MSB} 203580$; vi) 4-50 $\mu \mathrm{M}$ PD98059; vii) $10 \mu \mathrm{M}$ LY294002; viii) 3-15 $\mu \mathrm{M}$ genistein; ix) $1 \mathrm{nM}$ PKA inhibitor 14-22 amide; x) 1.4-7 $\mu \mathrm{M} \mathrm{W}-7$; xi) $10 \mu \mathrm{M}$ BAPTA-AM.

\section{$R T-P C R$ and real-time quantitative $R T-P C R$}

RT-PCR and real-time quantitative RT-PCR (qRT-PCR) were carried out as described previously (Jin \& $O^{\prime}$ Neill 2011). Mouse brain RNA was extracted using the RNeasy Mini Kit (Qiagen, Cat. No.74104). Mouse oocytes and embryos were collected from the reproductive tract and washed three times in cold PBS to remove the HEPES-HTF and transferred in minimal volume as a group of ten. Two-cell embryos for qRT-PCR were derived from culture of zygotes $18 \mathrm{~h}$ post-hCG for $42 \mathrm{~h}$ in i) control media alone; ii) $7 \mu \mathrm{M} \mathrm{W}-7$; iii) $10 \mu \mathrm{M} \mathrm{SB} 203580$ and iv); $7 \mu \mathrm{M}$ $\mathrm{W}-7+10 \mu \mathrm{M}$ SB203580. RNA was extracted by three repeats of freezing in liquid nitrogen and thawing with vortex. The RNA was purified using the RQ1 RNase-free DNase Kit (Promega). RNA from ten embryos was subjected to RT with $1 \mu \mathrm{M}$ allelespecific reverse primer. Negative controls were either reactions 
without reverse transcriptase or with the RNA sample replaced by diethylpyrocarbonate treated MilliQ water (to test for any RNA or DNA contamination). An internal positive control was used to test for the expression of Actb. Amplification of cDNA used sequence-specific primers for RT-PCR as follows: Actb 5'-CGTGGGCCGCCCTAGGCACCA, 3'-TTGGCCTTAGGGTTCAGGGGG (predicted transcript size

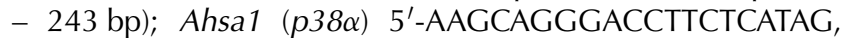
3'-ACACACACACACACAAACAC, $254 \mathrm{bp}$. Samples of each transcript were sequenced to confirm identity (SUPAMAC, Redfern, NSW, Australia).

Primers for qRT-PCR were: Actb 5'-CTAAGGCCAACCGTGAAAAG, 3'-GTACGACCAGAGGCATACAG (predicted transcript size - $109 \mathrm{bp}$ ); Hspab1 5'-GCTGTACCAGGGTGCGGGTG, 3'-ATCGGTGCCCAAGCAGCTATCA, 176 bp.

Real-time quantitative PCR analysis was carried out in a Stratagene Mx3000P cycler (Agilent Technologies, Santa Clara, CA). The PCR cycling were carried out under the following conditions: $95{ }^{\circ} \mathrm{C}$ for $10 \mathrm{~min}$, then 40 cycles with $95{ }^{\circ} \mathrm{C}$ for $15 \mathrm{~s}$, $60{ }^{\circ} \mathrm{C}$ for $30 \mathrm{~s}, 72{ }^{\circ} \mathrm{C}$ for $45 \mathrm{~s}$, acquire readings on channels appropriate for SYBR green label.

A threshold was set where the amplification was close to the reaction's maximum rate, which was not achieved in the negative controls. The threshold cycle $(C t)$ was used to calculate the relative quantity of the genes of interest in the cDNA sample. The $\Delta C \mathrm{t}\left(=C \mathrm{t}\left(\mathrm{Hspa}_{1} \mathrm{~b}\right)-\mathrm{Ct}(\right.$ Actb) $)$ was a measure of relative changes in $H$ spa 1 b mRNA content of the embryo. Data were normalised to the relative level of tissue mRNA by subtracting this samples $\Delta C$. A plot of $2^{- \text {(normalised } \Delta C t)}$ is shown.

\section{Immunofluorescence}

Immunofluorescence was carried out as previously described (Jin \& O'Neill 2007). After fixation and blocking, the embryos were incubated overnight at $4{ }^{\circ} \mathrm{C}$ with primary antibodies: $2 \mu \mathrm{g} / \mathrm{ml}$ mouse anti-ATF1 monoclonal IgA (Santa Cruz Biotechnology); $2 \mu \mathrm{g} / \mathrm{ml}$ rabbit anti-phospho-ATF1 (phospho S63) monoclonal [EP1591(2)Y] IgG (Abcam, Cambridge, UK); $2 \mu \mathrm{g} / \mathrm{ml}$ rabbit anti-P38 $\alpha$ polyclonal IgG) (Abcam); $2 \mu \mathrm{g} / \mathrm{ml}$ rabbit antiphospho-P38 $\alpha$ (phosphor $\mathrm{Y} 182+\mathrm{T} 180$ ) polyclonal IgG (Abcam) or $2 \mu \mathrm{g} / \mathrm{ml}$ mouse anti-CDX2 polyclonal IgG (BioGenex, Fremont, CA); $2 \mu \mathrm{g} / \mathrm{ml}$ mouse anti-BrdU monoclonal IgG (Sigma) or an equivalent concentration of isotype control non-immune immunoglobulin (negative control). Primary antibodies were detected by secondary antibodies coupled to Texas Red (goat anti-mouse Texas red conjugated IgA, Santa Cruz) or FITC (goat anti-rabbit FITC-conjugated IgG, Sigma) or Texas Red (goat anti-mouse Texas red-conjugated IgG, Abcam) for $1 \mathrm{~h}$ at room temperature. Nuclear localisation was determined by co-staining with $10 \mu \mathrm{g} / \mathrm{ml}$ of Hoechst 33342 (Sigma) or $0.1 \mu \mathrm{g} / \mathrm{ml}$ propidium iodine (Sigma). Whole section imaging was made with mercury lamp u.v. illumination and EPIfluorescence on a Nikon ECLIPSE 80i microscope with a Nikon Plan Apo $40 \times 1.0$ oil objective. These images were subjected to deconvolution using Sharpstack software (Image-Pro plusversion 6.3, Media Cybernetics, Inc., Silver Spring, MD, USA).

Quantitative analysis of immunostaining in the region of the nucleus was performed using the Histogram function within Image-Pro Plus. The area of the nucleus in each embryo was identified by DNA and outlined using the area of interest (AOI). This AOI was then used to measure the optical density of staining by the primary antibody of interest.

For each experiment, embryos from each treatment were processed at the same time and in parallel. All treatments were exposed to the same preparations and dilutions of all reagents including primary and secondary antibodies. Similarly, all preparations from an experiment were examined microscopically within the same session and identical microscope and camera settings were used. All image analysis was carried out in an identical manner for each embryo within an experiment. All preparations were carried out by the same experienced operator throughout the study.

\section{Western blot analysis}

Western blot analysis was carried out as described previously (Jin \& O'Neill 2010). Fresh zygote and embryos were collected and washed three times in cold PBS and then transferred to extraction buffer containing Triton X-100 (Bio-Rad), $24 \mathrm{mM}$ deoxycholic acid, $0.2 \%$ (w/v) SDS, $20 \mathrm{mMNaF}, 20 \mathrm{mMNa}_{4} \mathrm{P}_{2} \mathrm{O}_{7}$, $2 \mathrm{mM}$ phenylmethanesulphonylfluoride, $3.08 \mathrm{mM}$ aprotinin, $42 \mathrm{mM}$ leupeptin and $2.91 \mathrm{mM}$ pepstatin A (all purchased from Sigma) in PBS. Embryos were lysed by three cycles of freezing in liquid nitrogen and thawing (with vortexing). T47D cells (ATCC, HTB-133, Manassas, VA, USA) were harvested in DMEM (Gibco, Life Technologies Australia Pty Ltd, Mulgrave, VIC, Australia) medium. They were pelleted by centrifugation at $450 \mathrm{~g}$ for $5 \mathrm{~min}$ and then washed in cold PBS and pelleted by centrifugation for at least three times to remove the residual medium. The cells were transferred into extraction buffer $(1 \mathrm{ml}$ for $1 \times 10^{7}$ cells) and incubated at $4{ }^{\circ} \mathrm{C}$ for $10 \mathrm{~min}$ and then centrifuged at $8000 \mathrm{~g}$ for $10 \mathrm{~min}$ at $4{ }^{\circ} \mathrm{C}$. The supernatant containing the soluble proteins was transferred into a tube on ice. The extracted proteins were immediately subject to western blot analysis or stored at $-80{ }^{\circ} \mathrm{C}$ for future use. The samples were diluted with Laemmli-loading buffer and separated on $20 \%$ homogenous SDS-polyacrylamide gels (Amersham Pharmacia Biotech) using PhastSystem apparatus (PhastSystem separation and control unit, Pharmacia). The proteins were transferred onto polyvinylidene fluoride transfer membrane (Hybond-P, Amersham) with transfer buffer containing $12 \mathrm{mM}$ Tris (Sigma), 96 mM glycine (BDH, Sydney, NSW, Australia) and $20 \%(\mathrm{v} / \mathrm{v})$ methanol (BDH) by a semi-dry PhastTransfer system (Amersham Pharmacia Biotech). The membrane was incubated in $10 \mathrm{ml}$ of blocking buffer containing $2.5 \%(\mathrm{w} / \mathrm{v})$ skimmed milk powder (Diploma, Fronterra Foodservices, North Ryde, NSW, Australia) and then stained with $0.4 \mu \mathrm{g} / \mathrm{ml}$ rabbit antiP38 $\alpha$ MAP kinase IgG, $0.2 \mu \mathrm{g} / \mathrm{ml}$ rabbit anti-phosphor-P38 $\alpha$ MAP kinase IgG or $0.4 \mu \mathrm{g} / \mathrm{ml}$ rabbit anti-phospho-ATF1 monoclonal $\operatorname{lgG}$ in a blocking buffer at $4{ }^{\circ} \mathrm{C}$ overnight with agitating on a vortex mixer. Primary antibody was detected with 1:5000 HRP-conjugated secondary antibody (Sigma) and detected using chemiluminescence. The membrane was incubated in Super Signal West Femto (Pierce, Rockford, IL, USA) diluted 1:4. The membrane was stripped by incubation in $200 \mathrm{mM} \mathrm{NaOH}$ (Sigma) for $30 \mathrm{~min}$ at room temperature and reprobed with 1:1000 rabbit anti-actin, cytoplasmic 1 (actin) antibody (Sigma) in blocking buffer at $4{ }^{\circ} \mathrm{C}$ overnight on shaker. 
The bands were quantitatively analysed using Labworks software Ver 4.5 (UVP, Inc., Upland, CA, USA). Integrated optical density (IOD) of each band was measured. Relative IOD is the ratio of IOD of target band compared with the IOD of $\beta$-actin (loading control).

\section{Assessment of activation of embryonic transcription}

The zygotes $18 \mathrm{~h}$ post-hCG were cultured communally in GE-HTF medium supplemented with $0.05 \%$ DMSO, SB203580, W-7, SB203580 $+\mathrm{W}-7$ or $26 \mu \mathrm{M} \alpha$-amanitin to $44 \mathrm{~h}$ post-hCG. The two-cell embryos were collected and rinsed with $\mathrm{PBS}$, followed by incubation in physiological buffer (PB, $100 \mathrm{mM}$ potassium acetate, $30 \mathrm{mM} \mathrm{KCl}, 10 \mathrm{mM}$ $\mathrm{Na}_{2} \mathrm{HPO}_{4}, 1 \mathrm{mM} \mathrm{MgCl}$, $1 \mathrm{mM} \mathrm{Na}$ ATP, $1 \mathrm{mM}$ dithiothreitol and $0.2 \mathrm{mM}$ phenylmethylsulphonyl fluoride; $\mathrm{pH}$ 7.2) with $100 \mu \mathrm{g} / \mathrm{ml}$ BSA and $80 \mathrm{U} / \mathrm{ml}$ RNasin. The embryos were incubated on ice and permeabilised with PB containing $0.05 \%(\mathrm{v} / \mathrm{v})$ Triton $\mathrm{X}-100$ for $2 \mathrm{~min}$ at room temperature, followed by washing with $\mathrm{PB}$ and further incubation with transcription mix (PB supplemented with $100 \mu \mathrm{M}$ ATP, $100 \mu \mathrm{M}$ CTP, $100 \mu \mathrm{M}$ GTP, $100 \mu \mathrm{M}$ Br-UTP and $1 \mathrm{mM} \mathrm{MgCl}_{2}$ ). All chemicals used were cell culture-graded (Sigma). The labelling was performed for $15 \mathrm{~min}$ at $33^{\circ} \mathrm{C}$. Embryos were washed with $\mathrm{PB}$ and repermeabilised with $\mathrm{PB}$ containing $0.2 \%(\mathrm{v} / \mathrm{v})$ Triton $\mathrm{X}-100$ for $2 \mathrm{~min}$ at $4{ }^{\circ} \mathrm{C}$ and subsequently subject to immunofluorescence to detect BrdU staining.

\section{Developmental outcomes}

Developmental outcomes were assessed by recording the stages of morphological development at the times indicated, and nuclei of cells within embryos were stained with $10 \mu \mathrm{g} / \mathrm{ml}$ Hoechst 33342 (Sigma) to allow the total number of cells to be recorded.

\section{Statistical analysis}

The statistical analysis was performed using SPSS for Window (Version 19.0, SPSS, Inc.). The cell number, relative gene expression levels or staining intensity were analysed by univariate ANOVA. The statistical model incorporated cell number and intensity as the dependent variable and test compound concentrations as the independent variable. Experimental replicate was incorporated as a covariate. Tests of main factor and interaction effects were performed. Difference between individual test concentrations was assessed by the least significance test where indicated. Relative gene expression data was first subjected to arcsine transformation. Paired variables of the ratio of IOD of target band relative to IOD of $\beta$-actin and staining intensity were analysed by paired $t$-tests. The developmental rate of embryos to the blastocyst stage was assessed by binary logistic regression analysis.

\section{Results}

Immunolocalisation of ATF1 showed low levels of primarily cytoplasmic staining in oocytes and during the early stages of zygotic maturation (up to $18 \mathrm{~h}$ post-hCG). ATF1 staining began to accumulate within both the male and female pronuclei from the PN4 stages (22 $\mathrm{h}$ post-hCG; Fig. 1A). Staining was excluded from the nucleoli within each pronucleus (examples marked with arrows).
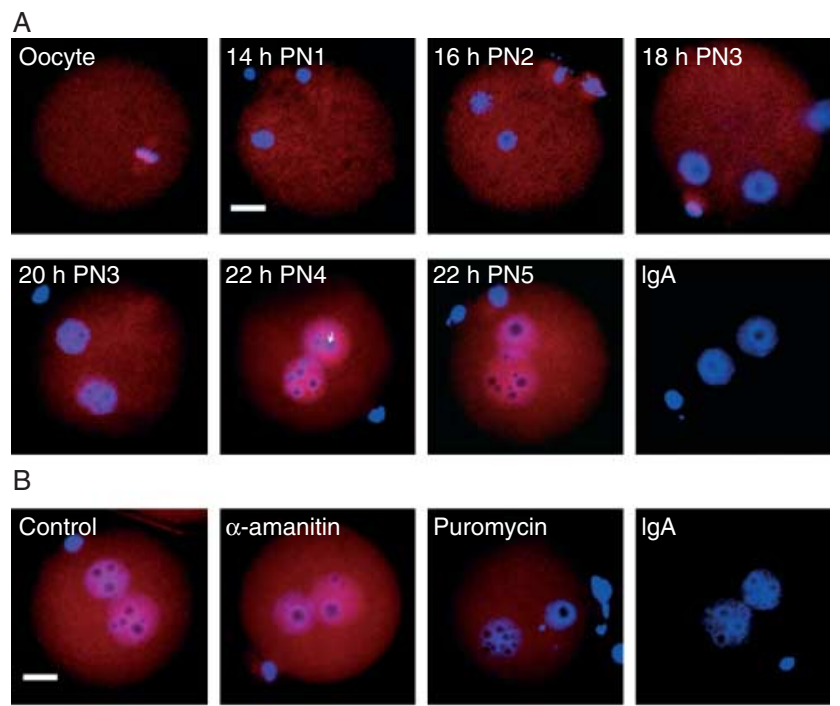

C
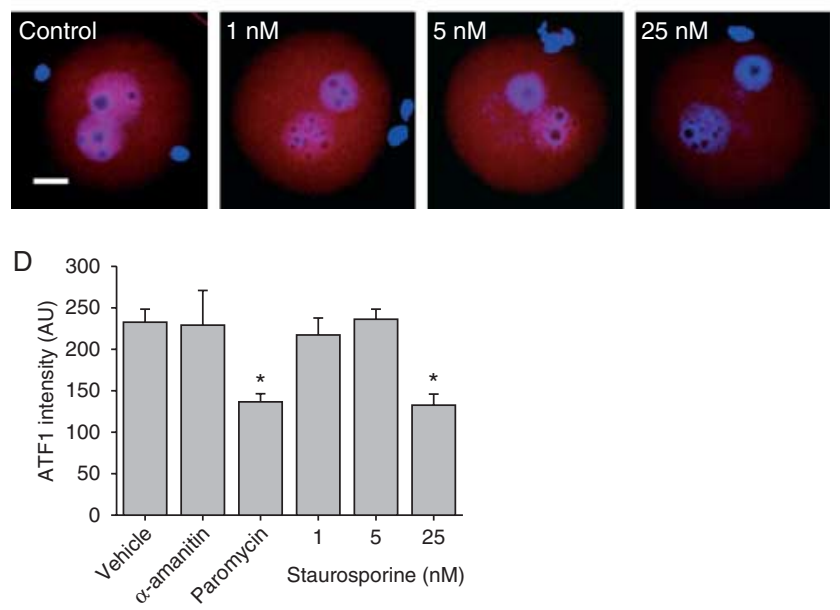

Figure 1 Expression patterns of ATF1 in mouse oocytes and zygotes. Merged epifluorescence images of ATF1 (red) and Hoechst 33342 (blue) counterstains (DNA) in hybrid oocytes and the zygotes collected from reproductive tracts from 14 to $22 \mathrm{~h}$ post-hCG. Negative control was the staining of non-immune IgA in the zygotes $(22 \mathrm{~h}$ post-hCG as an example). Scale bar $=10 \mu \mathrm{m}$ for all images. The images represent four independent replicates with at least 40 embryos per treatment. Hybrid zygotes $18 \mathrm{~h}$ post-hCG were cultured in (A) GE-HTF medium supplemented with (B) $26 \mu \mathrm{M} \alpha$-amanitin or $18.3 \mu \mathrm{M}$ puromycin or (C) a range of staurosporine doses from 1 to $25 \mathrm{nM}$ for $4 \mathrm{~h}$. Negative control was the staining of non-immune IgA in the zygotes (PN4 collected directly from the reproductive tract). Scale bar $=10 \mu \mathrm{m}$ for all images. (D) The mean intensity of ATF1 staining in each pronucleus of zygotes after treatment. ${ }^{*} P<0.001$, compared with the vehicle. The results are the mean \pm S.E.M. of four independent replicates with at least ten embryos/treatment in each replicate. AU, arbitrary units of optical density of staining. 
Pharmacological analysis of the regulation of this nuclear accumulation of ATF1 in zygotes was undertaken (Fig. 1B and C). The accumulation was not influenced by $\alpha$-amanitin $(P>0.05)$, but was significantly inhibited by puromycin $(P<0.001)$ (Fig. 1B and D). This indicates that nuclear accumulation of ATF1 did not require new transcription, but required a puromycin-dependent translational event for its full expression. Pronuclear accumulation of ATF1 was inhibited by the broad spectrum protein kinase inhibitor, staurosporine $(P<0.01$; Fig. $1 \mathrm{C}$ and $\mathrm{D})$. The identity of the kinases responsible for nuclear localisation of ATF1 was further assessed pharmacologically. The selective inhibitor of P38 (SB203580) blocked ATF1 pronuclear accumulation in a dose-dependent manner ( $P<0.001$; Fig. $2 \mathrm{~A}$ and $\mathrm{D})$. By contrast, an inhibitor of MEKs/ERKs (PD98059) had no effect $(P>0.05$; Fig. 2B and $D)$, nor did inhibitors of tyrosine kinase (genistein, Fig. $2 \mathrm{C}$ and $\mathrm{E}$ ), phosphatidylinositol-3-kinase (LY294002, Fig. 2C and E) or protein kinase A (PKA inhibitor 14-22 amide, Fig. 2C and E). Blocking calcium signalling (BAPTA-AM) or calmodulin activity (W-7) was also without effect (Fig. 2C and E), indicating that calmodulin-dependent kinases were not necessary for nuclear accumulation of ATF1. Signalling via the P38 MAP kinase pathway is primarily responsible for the nuclear accumulation of ATF1.

We next examined the localisation (Fig. $3 \mathrm{~A}$ ) and the levels of expression (western blot analysis) (Fig. 3B) of the phosphorylated form of ATF1 (pATF1). In the oocyte and zygote, there was a low level of generalised staining of pATF1 throughout the cytoplasm, with only a modest level of pronuclear accumulation of the phosphorylated form. At the two-cell stage, however, intense nuclear pATF1 staining was observed (Fig. 3A), and the level of total pATF1 relative to housekeeper gene product $\beta$-ACTIN was higher than that in one-cell stage $(P<0.05)$ (Fig. 3B). This nuclear accumulation of ATF1 persisted in eight-cell and blastocyst stages. In blastocysts, pATF1 was present within both the inner cell mass and trophectodermal cells (the trophectoderm being identified by co-staining with the lineage-specific marker CDX2) (Fig. 3C).

Nuclear localisation and phosphorylation of the related CREB transcription factor were depended on the actions of autocrine embryotropins (Jin \& O'Neill 2010). The culture of embryos in vitro reduces this tropic stimulation, but communal culture can improve this: individual culture causes dilution of the autocrine embryotropins in media and therefore results in reduced tropic stimulation ( $\mathrm{O}^{\prime}$ Neill 2008a,b). The culture of zygotes to the two-cell stage resulted in reduced pATF1 staining within the nuclei and whole embryos compared with two-cell embryos collected from the reproductive tract (Fig. 4A-i and ii), and this reduction was greater when embryos were cultured individually compared with communal culture (Fig. 4iii). The addition of a known embryotropin (Paf) to media significantly reversed the effects of individual culture on the level of pATF1 staining
A
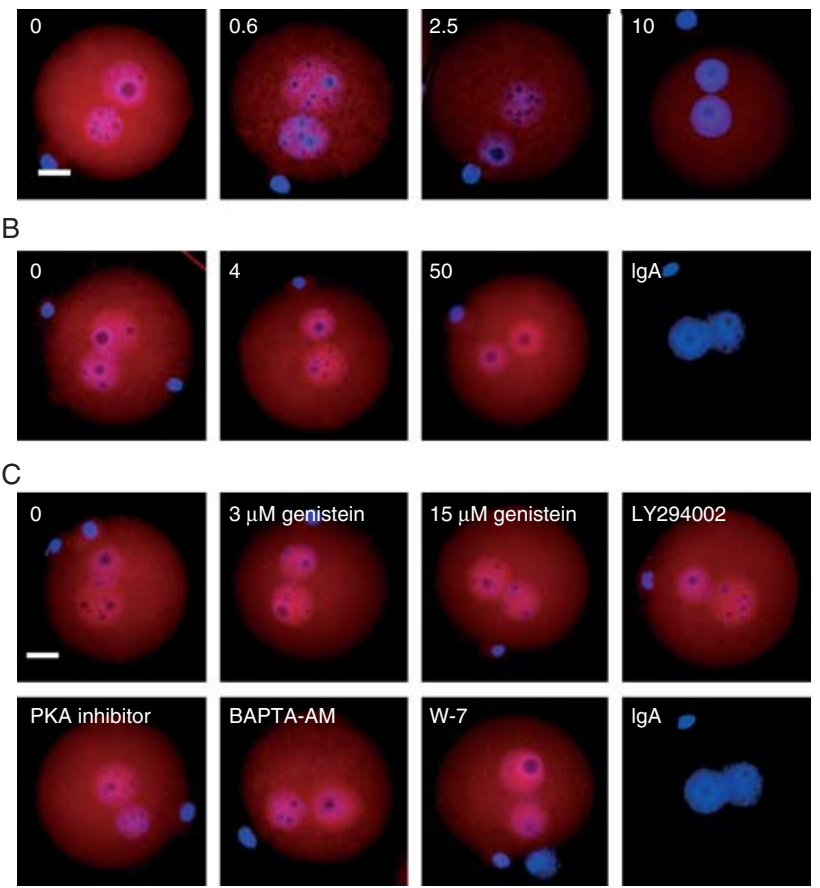

D
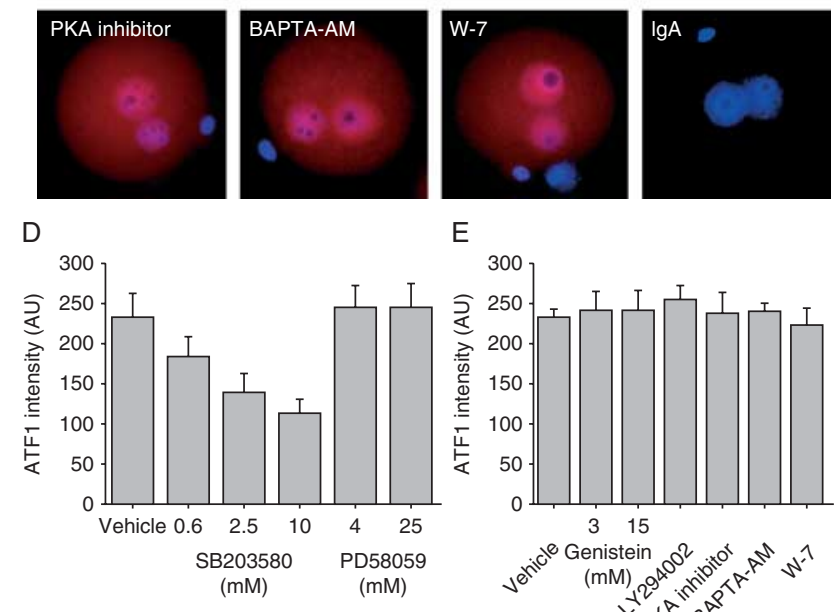

E

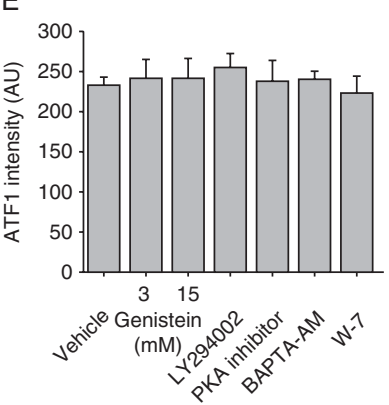

Figure 2 The effects of protein kinase inhibitors on ATF1 expression in zygotes. Merged epifluorescence image of ATF1 (red) and Hoechst 33342 (blue) (DNA) staining of zygotes (18 h post-hCG) treated for $4 \mathrm{~h}$ with (A) 0.6-10 $\mu \mathrm{M}$ SB203580, (B) 4-50 $\mu \mathrm{M}$ PD98059 and (C) 3$15 \mu \mathrm{M}$ genistein, $10 \mu \mathrm{M}$ LY294002, 1 nM PKA inhibitor 14-22 amide, $10 \mu \mathrm{M}$ BAPTA-AM and $7 \mu \mathrm{M}$ W-7. The images represent three independent replicates for ATF1 and Hoechst 33342 staining, with atleast 40 embryos per treatment. Scale bar $=10 \mu \mathrm{m}$ for all images. (D) The mean intensity of ATF1 staining in each pronucleus of zygotes after treatment with SB203580 or PD58059. Univariate analysis indicated a significant dose-dependent effect of SB203580 $(P<0.001)$ but not PD58059 $(P>0.05)$. The results are the mean \pm S.E.M. of four independent replicates with atleast ten embryos/treatment in each replicate. (E) The mean intensity of ATF1 staining in each pronucleus of zygotes after treatment of the inhibitors is shown. None of the treatments caused a significant reduction in staining compared with vehicle controls $(P>0.05)$. The results are from three independent replicates and each treatment had atleast ten embryos. AU, arbitrary units of optical density of staining.

$(P<0.001$; Fig. 4A-iv and B). This beneficial effect of Paf on PATF1 was inhibited by the calmodulin inhibitor, $W-7$ (Fig. 4A-v, vi and C; $P<0.001$ ).

This analysis of the beneficial effect of communal culture on phosphorylation of ATF1 was extended to 

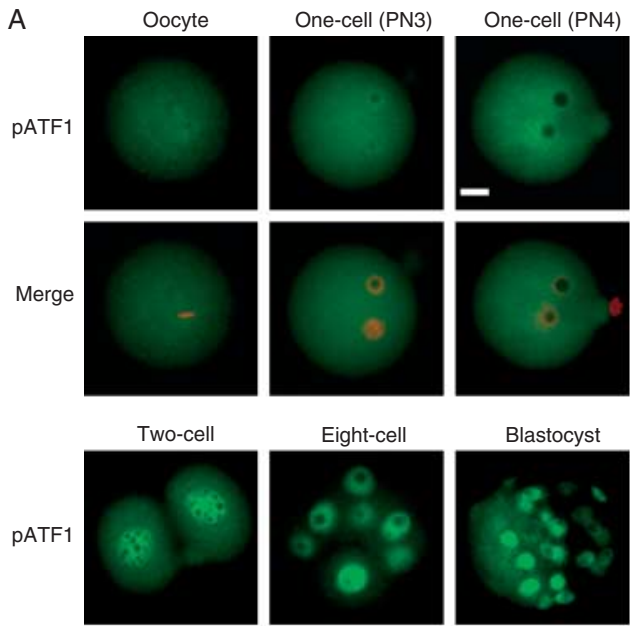

Blastocyst

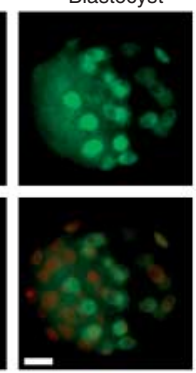

C

$\mathrm{B}$
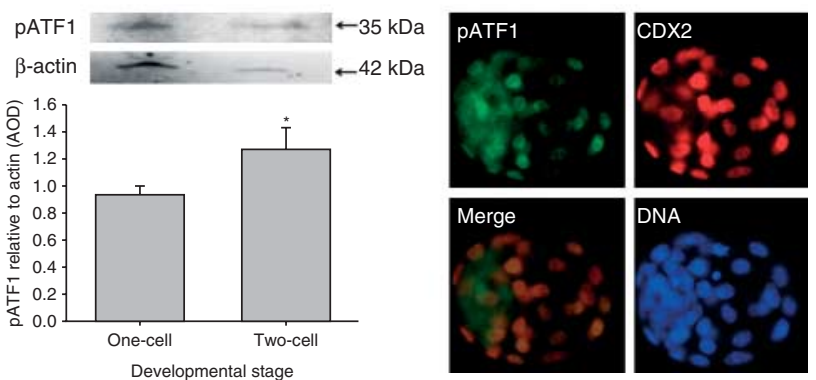

Figure 3 The expression of pATF1 in preimplantation embryos. (A) Epifluorescence images of pATF1 staining and corresponding merged images of pATF1 counterstained with propidium iodide (DNA) (merge) in oocytes, zygotes (PN3 and PN5) and preimplantation embryos collected from reproductive tracts. Negative control was the staining of non-immune IgG in the zygotes and blastocyst as examples. The results were representative of three replicates with at least 40 oocytes or embryos of each stage. Scale bar $=10 \mu \mathrm{m}$ for all images. (B) Western blot analysed pATF1 in zygote and two-cell embryo stage and reprobed for $\beta$-actin as loading control and the ratio of pATF1 IOD relative to actin was plot. The results represented for independent replicates and each lane had 90 embryos $* P<0.01$. (C) The images are of pATF1, CDX2, merge images of pATF1 and CDX2, and Hoechst 33343 counterstaining for DNA. Negative controls were the staining of non-immune IgG (not shown). The results are representative of atleast 20 blastocysts/treatment.

assess whether P38 MAP kinase and calmodulin may interact at this level. Treatment with SB203580 $(10 \mu \mathrm{M}$, $P<0.001$; Fig. 5Aii) or $\mathrm{W}-7$ (7 $\mu \mathrm{M}, P<0.05$; Fig. 5Aiii) significantly reduced both the total and nuclear levels of pATF1 staining in two-cell embryos derived from the communal culture of zygotes (Fig. 5A and B). There was a further significant inhibition of this staining when W-7 and SB203580 treatments were combined (Fig. 5A-iv; $P<0.001)$, and this affected both the total and nuclear levels of ATF1. This result implicates a role for embryotropic signalling, acting via both P38 MAP kinase and calmodulin-mediated signalling pathways, in the phosphorylation and therefore activation of ATF1.

Calmodulin expression is well established in the early embryo and we demonstrate P38 $\alpha$ transcripts were
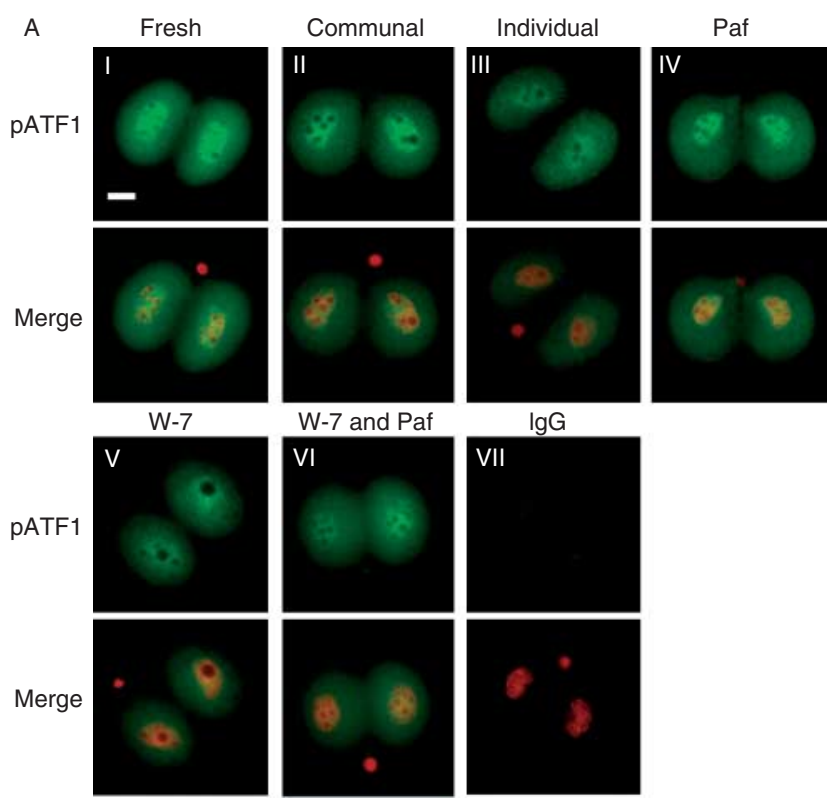

W-7 and Paf
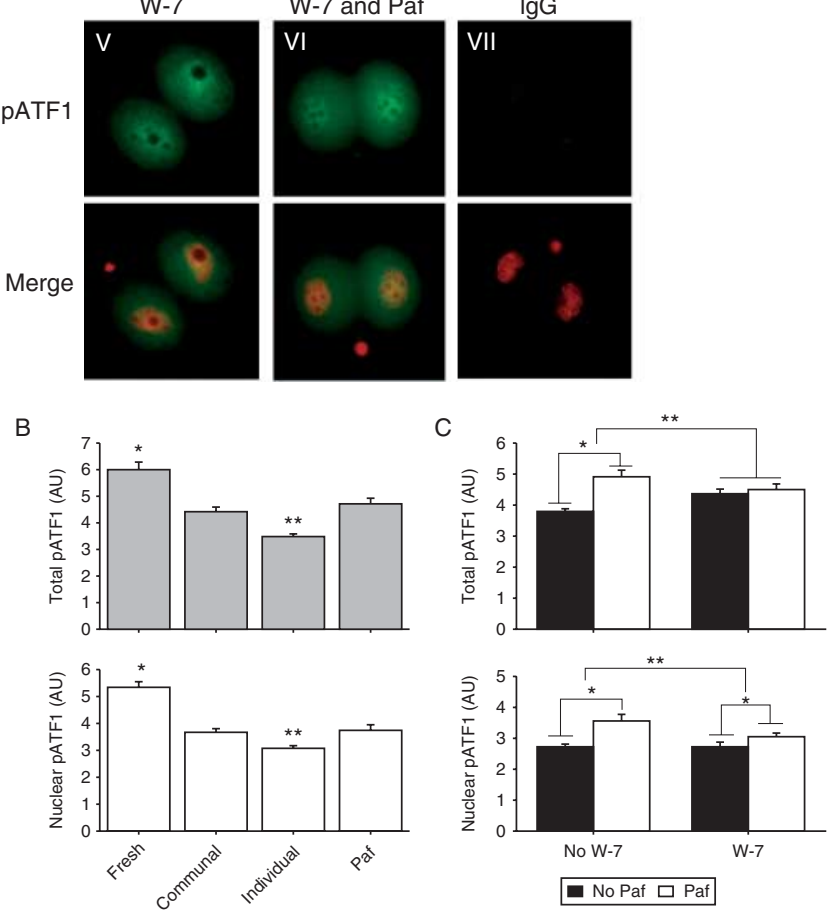

Figure 4 Regulation of ATF1 phosphorylation in two-cell embryos. Epifluorescence images of pATF1 staining and corresponding merged images of pATF1 counterstained with propidium iodide (DNA) (merge) in the two-cell embryos. (A) (i) Two-cell embryos collected directly from the reproductive tract, those collected as zygotes and (ii) cultured communally (ten embryos in $10 \mu \mathrm{l}$ media), (iii) individually in $10 \mu \mathrm{l}$ of media, (iv) individually with Paf, (v) individually with W-7 (7 $\mu \mathrm{M})$ and (vi) individually with $\mathrm{W}-7$ and Paf. (vii) Negative control was the nonimmune IgG staining of freshly collected two-cell embryos. (B) The intensity of pATF1 in the whole cell and in each nuclei of the two-cell embryos (arbitrary units (AU) of optical density of staining) $* P<0.000$, compared with other three treatments; ${ }^{* *} P<0.05$, compared with communal group and ${ }^{* *} P<0.001$, compared with Paf group $(\mathrm{C})$ The intensity of pATF1 staining in whole cells or nuclei after treatment with exogenous Paf with or without W-7 $(7 \mu \mathrm{M})$. $P<0.01{ }^{* *} P<0.001$ for the comparisons shown. The results are from three independent replicates and each treatment had atleast 30 embryos. 

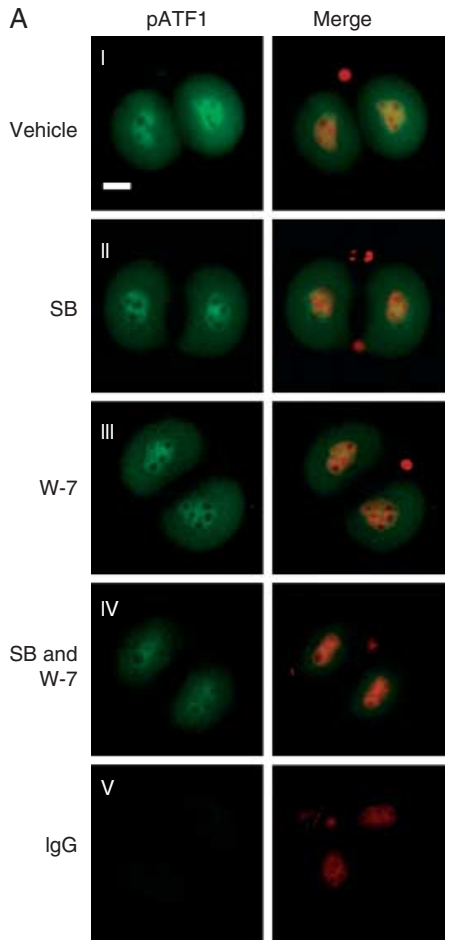

B
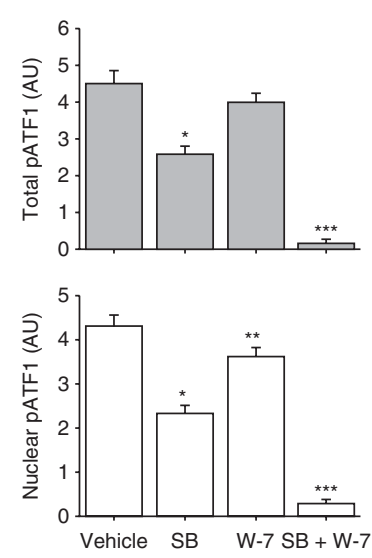

Figure 5 The effect of inhibitors of calmodulin and P38 MAP kinase on pATF1 staining. (A) Epifluorescence images of pATF1 staining and corresponding merged images of pATF1 counterstained with propidium iodide (DNA) (merge) in the two-cell embryos cultured in media with (i) $0.05 \%$ DMSO (vehicle), (ii) SB203580, (iii) $7 \mu \mathrm{M} \mathrm{W}-7$, and (iv) $10 \mu \mathrm{M}$ SB203580 and $7 \mu \mathrm{M} \mathrm{W}-7$. (v) Negative control was the non-immune IgG staining in vehicle embryo as an example. The results represent three independent replicates and each treatment had atleast 30 embryos. Scale bar $=10 \mu \mathrm{m}$ for all images. (B) The intensity of pATF1 in the whole cell and in nuclei of the two-cell embryos expressed as arbitrary units $(\mathrm{AU})$ of optical density of staining $* P<0.05 * * P<0.01$, $* * * P<0.001$ compared with vehicle.

detected in mouse oocytes, and all preimplantation stage embryos collected directly from the reproductive tract (Fig. 6A) confirming earlier findings (Natale et al. 2004). Western blot analysis detected a single band for P38 $\alpha$ or phospho-P38 $\alpha$ MAP kinase (pP38 $\alpha$ ) in the zygotes of 16 and $22 \mathrm{~h}$ post-hCG (Fig. 6B). Using the same antibodies, immunofluorescence staining detected $\mathrm{P} 38 \alpha$ and pP38 $\alpha$ throughout the cytoplasm of oocytes, zygotes and two-cell embryos. Nuclear accumulation of P38 MAP kinase (Fig. 6C) and pP38 (Fig. 6D) commenced from the PN2 stage and was extensive in the nucleus of the two-cell embryo.

The expression of calmodulin and P38 MAP kinase in the early embryo and the marked effects that inhibition of these two pathways has on the activation (phosphorylation) of CREB and ATF1 encourage the hypothesis that these pathways may act in concert to regulate the activation of transcription from the embryonic genome. We have previously demonstrated that CREB activation induced the transcription of canonical CREB-responsive genes, $B C l 2$ and $C F O S)$ at the time of embryonic genome activation (EGA) (Jin \& O'Neill 2011). Hspa1b (formerly known as Hsp70.1) is a well-characterised early product of EGA and its expression is widely used as a marker of EGA (Christians et al. 1995). Both SB203580 and W-7 caused a significant inhibition $(P<0.01)$ of the expression of this marker gene in two-cell embryos. Combining both these inhibitors caused strong inhibition relative to the vehicle control $(P<0.001$; Fig. $7 \mathrm{~A}$ and $\mathrm{E})$, but there was not a further significant additive effect compared with either inhibitor alone. Total RNA synthesis was assessed by the incorporation of BrdUTP into the embryos during the two-cell stage.

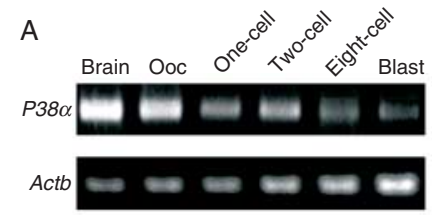

B

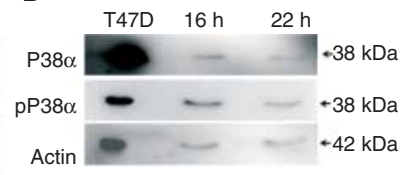

C P38 $\alpha$
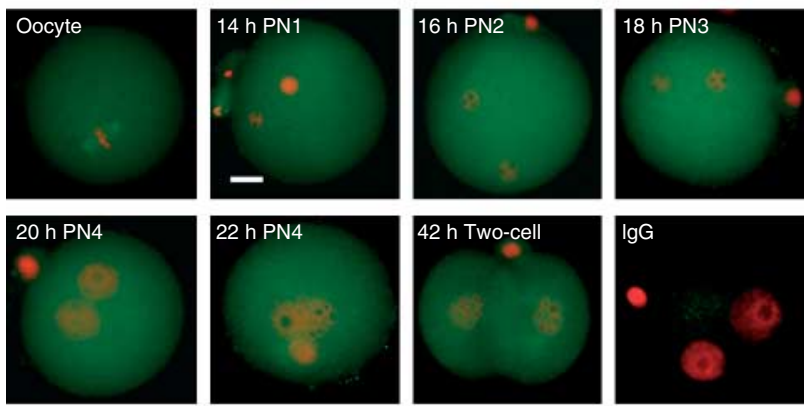

$\mathrm{D} p \mathrm{pP} 3 \alpha$
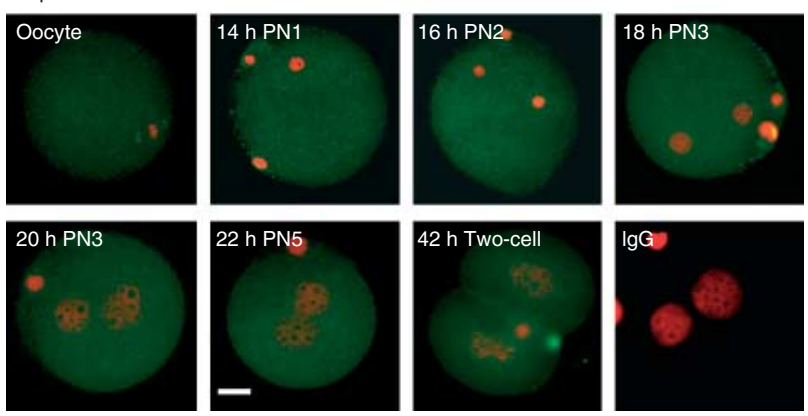

Figure 6 P38 MAP kinase- $\alpha$ (P38 $\alpha$ ) and phospho-P38 MAP kinase- $\alpha$ $(\mathrm{PP} 38 \alpha)$ in the mouse oocytes and zygotes. (A) RT-PCR analysis of the expression of $P 38 \alpha$ transcripts in mouse oocytes and preimplantation embryos. Positive controls were the expression of the gene in mouse brain and housekeeper gene Actb in the brain, oocytes and embryos. Negative controls were the reactions without reverse transcriptase and without RNA (not shown). Results represent three independent replicates. Each band is RNA from one oocyte or embryo equivalent. (B) Western blot analysis of P38 $\alpha$ and pP38 $\alpha$ in T47D cells (control) and mouse zygotes 16 and $22 \mathrm{~h}$ post-hCG. Each lane contained 1000 cells or 90 embryos. (C) The merged images of epifluorescence staining of P38 $\alpha$ and (D) pP38 $\alpha$ and counterstaining of DNA in oocyte, zygotes $14-22 \mathrm{~h}$ post-hCG and two-cell embryo. Negative controls were staining of non-immune IgG. The oocytes and the each stage zygotes had atleast 20 embryos. Scale bar $=10 \mu \mathrm{m}$ for all images. 

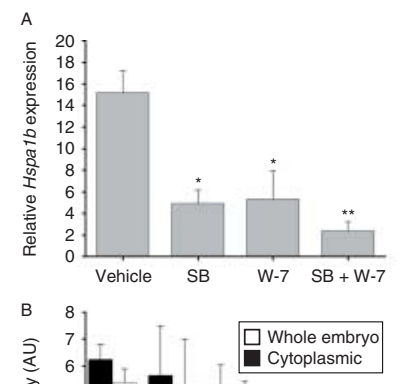

D
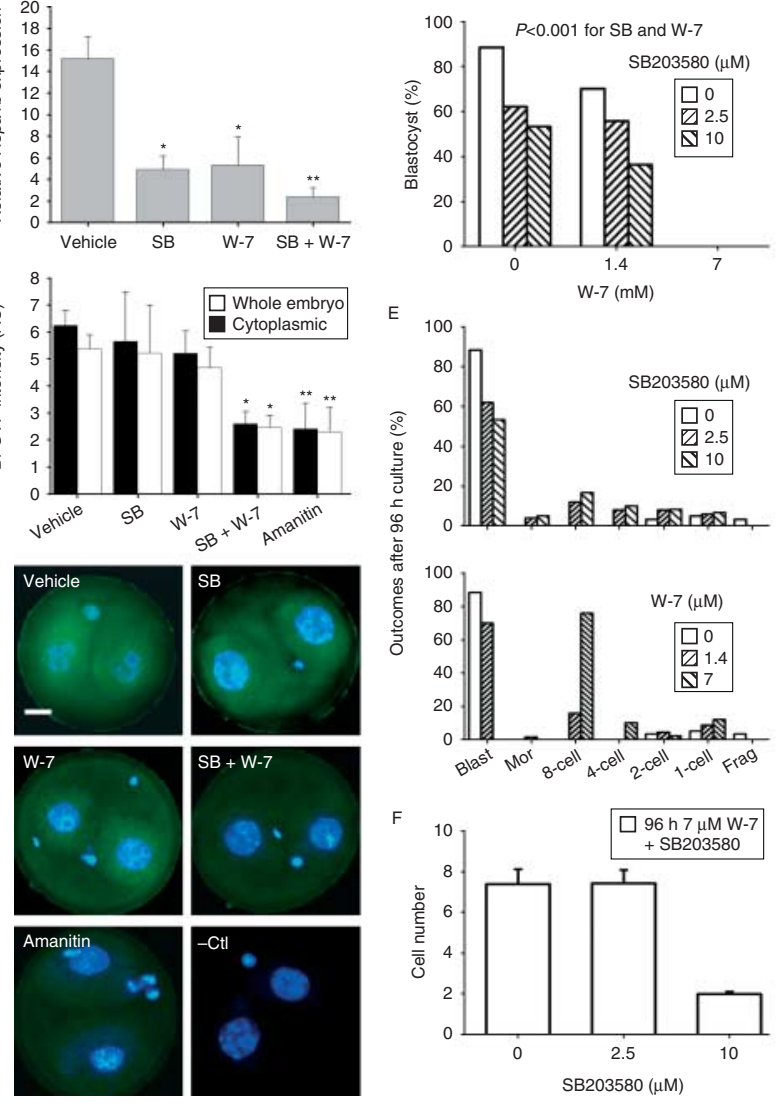

Figure 7 The effect of inhibitors of P38 MAP kinase and calmodulin on zygote development in vitro. The effects of the inhibitors of P38 and calmodulin on EGA were tested on two-cell embryos that were derived from the zygotes after treatment (A, B and C). (A) The results were the normalised $\Delta-\Delta C$ t of $H$ spa 1 b expression for five independent replicates and each reaction had cDNA equivalent to 0.32 embryo amplified. ${ }^{*} P<0.01$, compared with vehicle control; ${ }^{* *} P<0.001$, compared with vehicle control. (B) The intensity of BrdU staining in the whole embryo and cytoplasm was measured. ${ }^{*} P<0.001$, compared with either the vehicle or SB203580 or $W-7$; ${ }^{* * P}<0.001$, compared with the vehicle; there was no significant difference between the treatment with $\alpha$-amanitin and both inhibitors. (C) Representative merged images of BrdU and Hoechst 33342 staining. Scale bar $=10 \mu \mathrm{m}$ for all images. (D) The proportion of zygotes that developed to morphological blastocysts after $96 \mathrm{~h}$ culture in varying concentrations of W-7 and SB203580; (E) The stage that embryos blocked after culture in SB203580 or W-7 and $(F)$ the number of cells in embryos cultured for $96 \mathrm{~h}$ in the presence

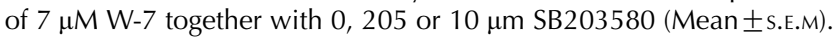

Neither SB203580 nor W7 adversely affected the staining levels of BrdUTP, but when used together they caused a $>50 \%$ reduction $(P<0.001)$. This reduction was similar to that caused by treatment with the RNA polymerase inhibitor, $\boldsymbol{\alpha}$-amanitin. These results implicate roles for the combined actions of the P38 MAP kinase and calmodulin in the activation of the embryonic transcription in the mouse two-cell embryo. The culture of zygotes in either the P38 MAP kinase inhibitor (SB203580) or calmodulin inhibitor (W7) both caused a significant dose-dependent reduction in the proportion of zygotes that developed to morphological blastocysts $(P<0.001$; Fig. 7D). There was a statistically significant interaction effect on embryo development of these two inhibitors. The highest dose treatment with W7 alone resulted in a predominantly eight-cell block, while SB203580 resulted in retarded development there was no apparent block at a specific stage of development (Fig. 7E and F). Combined treatment with W7 (7 $\mu \mathrm{M})$ and SB203580 $(10 \mu \mathrm{M})$ induced a complete two-cell block (Fig. 7E and F). This observation of a two-cell block when both calmodulin and P38 MAP kinase are inhibited is consistent with the known effects of blocking EGA.

\section{Discussion}

The ATF1 transcription factor accumulated in each pronucleus during zygotic maturation and then remained within the nucleus at subsequent stages of development. To become an active transcription factor, ATF1 must first become phosphorylated (Gupta \& Prywes 2002). Phosphorylation was first observed in the late stages of zygotic maturation and became most obvious from the two-cell stage. Both the nuclear localisation of ATF1 into the pronuclei of zygotes and the accumulation of PATF1 into the nuclei of the two-cell embryo required the actions of P38 MAP kinase, as assessed by their inhibition by SB203580. While calmodulin-dependent signalling was not required for ATF1 nuclear localisation in the zygotes, it did act in concert with the P38 MAP kinase pathway to maximise the level of phosphorylated ATF1 in the nucleus at the two-cell stage.

This nuclear accumulation of ATF1 required protein synthesis but not $\alpha$-amanitin-sensitive transcription, which implies that new ATF1 is synthesised after fertilisation from maternal stores of mRNA. Inhibition of protein synthesis by puromycin reduced both the total levels and nuclear accumulation of ATF1 in the zygote, but inhibition of P38 MAP kinase by SB203580 only blocked its nuclear accumulation. By contrast, the maximum phosphorylation of ATF1 required the combined actions of both calmodulin and P38 MAP kinase-dependent signalling pathways. These results point to three levels of control of the localisation and activation of the ATF1 transcription factor in the nucleus of the two-cell embryo (Fig. 8): i) the activation of its protein synthesis soon after fertilisation, ii) its P38 MAP kinase-dependent accumulation within both pronuclei during zygotic maturation, which is iii) followed by its calmodulin and P38 MAP kinase-dependent activation by phosphorylation, particularly in the two-cell embryo by the time of EGA. In an earlier study (Jin \& O'Neill 2010) we did not find any effect of Paf on pATF1 but that result used an antibody that cross-reacted with both pCREB and pATF1 and gave a weak signal for pATF1. This current result used an antibody specific for pATF1 and this increased specificity probably accounts for the different result. 
Calmodulin is a universal intracellular mediator of calcium function, which is known to have essential roles in the regulation of normal compaction and cavitation of the embryo (Ohsugi et al. 1993, Wilding et al. 1995). P38 is known to have roles in the process of compaction at the eight-cell stage, blastocyst cavitation and tight junction function during mouse preimplantation development (Natale et al. 2004, Paliga et al. 2005, Maekawa et al. 2007, Bell \& Watson 2013). Our observation that inhibition of P38 MAP kinase or calmodulin alone predominantly caused an eight-cell block to development is consistent these known roles. Yet, the two-cell block induced by inhibition of both calmodulin and P38 MAP kinase demonstrates that both these pathways have essential roles at the two-cell stage, but that there is some level of mutual dependency on their actions at this stage, but not later in development. This might be explained in part by the roles that the two pathways play in the activation of ATF1 and CREB. Both these CREB-family members are essential but functionally redundant for early embryo development. The inhibition of calmodulin blocks the activation of CREB but still allows partial P38 MAP kinase-mediated activation of ATF1, while inhibition of P38 MAP kinase blocks ATF1 action but not CREB. The inhibition of both ATF1 and CREB occurs when both pathways are inhibited, and this is associated with a failure of the normal EGA and a two-cell block. It is of interest that the double knockout of Atf1 and Creb does not result in embryonic lethality until around the blastocyst stage (Bleckmann et al. 2002). This is probably accounted for by the fact that the knockouts are achieved from heterozygous crosses, which means that maternal stores of mRNA of either of the transcription factors will persist in the null-allele embryos across the early stages of development and thus disguise the roles for the transcription factors at the two-cell stage. Both P38 MAP kinase and calmodulin target many proteins apart from ATF1 and CREB and so other roles for these signalling pathways in regulating progression through the two-cell stage cannot be excluded; however, the observations that blocking both these pathways blocked EGA and that the expression of defined canonical CREBfamily response genes occurs at the time of EGA (Jin \& $\mathrm{O}^{\prime}$ Neill 2011) support the hypothesis that the combined actions of CREB and ATF1 form a part of the transcriptional machinery required for $\mathrm{EGA}$, and that one role of the P38 MAP kinase and calmodulin signalling pathways is to act in concert to activate the ATF1/CREB transcription factors at the time of EGA. Both CREB and ATF1 homodimers bind to the CRE sequences in the promoter regions of many genes, but they can also heterodimerise to form an active transcription factor. So one possible mechanism for the apparent functional redundancy of these two transcription factors may lie in their capacity to form heterodimeric transcription factors. The CRE consensus binding site for these transcription factors is present within $\sim 4000$ promoters (Zhang et al. 2005), hence the activated presence of these two essential transcription factors at the time of EGA provides for the activation of a diverse transcriptome and may account for the significant reduction in the levels of transcription observed when both calmodulin and P38 MAP kinase were blocked in the two-cell embryo (Fig. 8).

Culture of zygotes individually is known to cause reduced levels of autocrine tropic signalling due to their dilution in the surrounding media (O'Neill 2005). This treatment reduced the levels of pATF1 staining within nuclei of two-cell embryos, while the addition of the defined autocrine embryotropin, Paf, to culture media compensated for this. This indicates that embryotropic signalling is at least partly responsible for this nuclear accumulation of activated (phosphorylated) ATF1. Furthermore, the accumulation of pCREB within the nucleus in the two-cell embryos is also under this form of

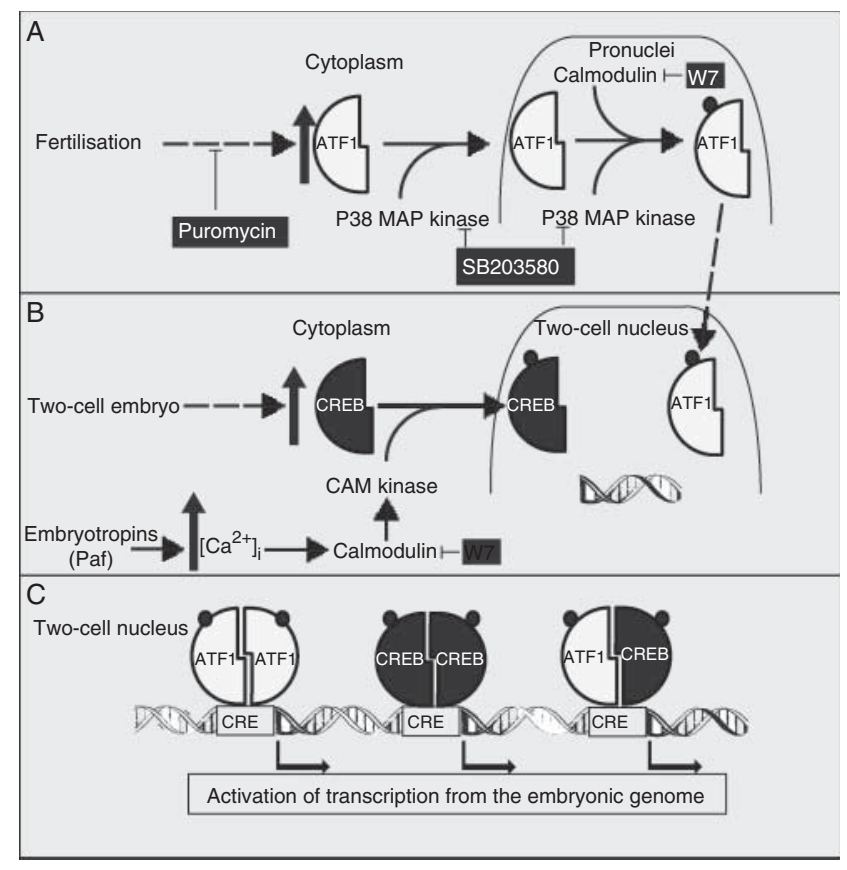

Figure 8 Hypothetical regulatory pathways for the activation of ATF1 and CREB mediated transcription in the early embryo. (A) Fertilisation leads to a puromycin-sensitive increase in ATF1 synthesis followed by P38 MAP kinase-sensitive accumulation and phosphorylation (solid, black circle) of ATF1 in both pronuclei in the late stage zygote. (B) Accumulation of phosphorylated ATF1 persists in the 2-cell nucleus and increased CREB synthesis commences at this stage. Phosphorylation and nuclear accumulation of ATF1 and CREB is promoted by the activity of autocrine embryotropins (including Paf) via an increased concentration of cytoplasmic calcium $\left(\left[\mathrm{Ca}^{2+}\right]_{i}\right)$ resulting in the activation of calmodulin (inhibited by W7) and calmodulin-dependent kinases (CAM kinase). (C) Phosphorylated ATF1 and CREB can form heterodimers or homodimer which bind to the CRE consensus sequence present in up to 4000 gene promoters, leading to formation of an extensive transcriptome that forms part of embryonic genome activation. 
control (Jin \& $\mathrm{O}^{\prime}$ Neill 2010). A range of embryotropins are known to activate PI3-kinase-mediated, calcium/ calmodulin-dependent signalling pathways (Lu et al. 2004, Li et al. 2007, O'Neill 2008a,b) and the current demonstration of the W7-dependent activation of ATF1 adds to the known downstream targets of this form of tropic stimulation (Jin \& O'Neill 2011).

P38 is also known to have roles in the process of compaction at the eight-cell stage, blastocyst cavitation and tight junction function during mouse preimplantation development (Natale et al. 2004, Paliga et al. 2005, Maekawa et al. 2007, Bell \& Watson 2013). Calmodulin is a universal intracellular mediator of calcium function. It is a crucial component in the regulation of preimplantation development and its actions are required for normal compaction and cavitation (Ohsugi et al. 1993, Wilding et al. 1995). Our observation that inhibition of calmodulin caused an eight-cell block to development is consistent with an important role for calmodulin in compaction. Yet, the two-cell block induced by inhibition of both calmodulin and P38 MAP kinase shows that critical roles for calmodulin occur earlier in development but do so in concert with other pathways. This study and an earlier study (Jin \& O'Neill 2011) add to the known functions of P38 MAP kinase and calmodulin to show that they act in concert to activate and promote the nuclear accumulation of two essential transcription factors at the time of EGA.

The study shows that accumulation of the essential ATF1 transcription factor commences in the late stages of zygotic maturation and persists across subsequent stage of preimplantation embryo development. This accumulation was dependent upon new protein synthesis and the actions of P38 MAP kinase. Activation via phosphorylation of the transcription factor occurred a little later, being evident in the two-cell stage embryo. This required the synergistic actions of both the P38 MAP kinase and calmodulin pathways and the actions of autocrine embryotropins. The presence of both activated forms of the essential and also mutually redundant ATF1 and CREB transcription factors within the nucleus at the time of EGA makes these transcription factors the attractive candidates for further investigation into their roles in this poorly understood process.

\section{Declaration of interest}

The authors declare that there is no conflict of interest that could be perceived as prejudicing the impartiality of the research reported.

\section{Funding}

This work was supported by grants form the Australian National Health And Medical Research Council to C O'Neill.

\section{References}

Adenot PG, Mercier Y, Renard JP \& Thompson EM 1997 Differential H4 acetylation of paternal and maternal chromatin precedes DNA replication and differential transcriptional activity in pronuclei of 1-cell mouse embryos. Development 124 4615-4625.

Bell CE \& Watson AJ 2013 p38 MAPK regulates cavitation and tight junction function in the mouse blastocyst. PLOS ONE 8 e59528. (doi:10.1371/ journal.pone.0059528)

Bleckmann SC, Blendy JA, Rudolph D, Monaghan AP, Schmid W \& Schutz G 2002 Activating transcription factor 1 and CREB are important for cell survival during early mouse development. Molecular and Cellular Biology 22 1919-1925. (doi:10.1128/MCB.22.6.1919-1925.2002)

Christians E, Campion E, Thompson EM \& Renard JP 1995 Expression of the HSP 70.1 gene, a landmark of early zygotic activity in the mouse embryo, is restricted to the first burst of transcription. Development 121 113-122.

Chrivia JC, Kwok RP, Lamb N, Hagiwara M, Montminy MR \& Goodman RH 1993 Phosphorylated CREB binds specifically to the nuclear protein CBP. Nature 365 855-859. (doi:10.1038/365855a0)

Collier M, O'Neill C, Ammit AJ \& Saunders DM 1990 Measurement of human embryo-derived platelet-activating factor (PAF) using a quantitative bioassay of platelet aggregation. Human Reproduction 5 323-328.

Gonzalez GA \& Montminy MR 1989 Cyclic AMP stimulates somatostatin gene transcription by phosphorylation of CREB at serine 133. Cell 59 675-680. (doi:10.1016/0092-8674(89)90013-5)

Gupta P \& Prywes R 2002 ATF1 phosphorylation by the ERK MAPK pathway is required for epidermal growth factor-induced c-jun expression. Journal of Biological Chemistry 277 50550-50556. (doi:10.1074/jbc. M209799200)

Hagiwara M, Brindle P, Harootunian A, Armstrong R, Rivier J, Vale W, Tsien R \& Montminy MR 1993 Coupling of hormonal stimulation and transcription via the cyclic AMP-responsive factor CREB is rate limited by nuclear entry of protein kinase A. Molecular and Cellular Biology 13 4852-4859.

Jin XL \& $\mathbf{O}^{\prime}$ Neill C 2007 cAMP-responsive element-binding protein expression and regulation in the mouse preimplantation embryo. Reproduction 134 667-675. (doi:10.1530/REP-07-0249)

Jin XL \& $\mathbf{O}^{\prime}$ Neill C 2010 The presence and activation of two essential transcription factors (CAMP response element-binding protein and cAMPdependent transcription factor ATF1) in the two-cell mouse embryo. Biology of Reproduction 82 459-468. (doi:10.1095/biolreprod.109.078758)

Jin XL \& $\mathbf{O}^{\prime}$ Neill C 2011 Regulation of the expression of proto-oncogenes by autocrine embryotropins in the early mouse embryo. Biology of Reproduction 84 1216-1224. (doi:10.1095/biolreprod.109.078758)

Kee BL, Arias J \& Montminy MR 1996 Adaptor-mediated recruitment of RNA polymerase II to a signal-dependent activator. Journal of Biological Chemistry 271 2373-2375. (doi:10.1074/jbc.271.5.2REF20=10.1242/ dev.003756)

Korzus E, Torchia J, Rose DW, Xu L, Kurokawa R, Mclnerney EM, Mullen TM, Glass CK \& Rosenfeld MG 1998 Transcription factor-specific requirements for coactivators and their acetyltransferase functions. Science 279 703-707. (doi:10.1126/science.279.5351.703)

Kwok RP, Lundblad JR, Chrivia JC, Richards JP, Bachinger HP, Brennan RG, Roberts SG, Green MR \& Goodman RH 1994 Nuclear protein CBP is a coactivator for the transcription factor CREB. Nature 370 223-226. (doi:10.1038/370223a0)

Li Y, Chandrakanthan V, Day ML \& O'Neill C 2007 Direct evidence for the action of phosphatidylinositol $(3,4,5)$-trisphosphate-mediated signal transduction in the 2-cell mouse embryo. Biology of Reproduction 77 813-821. (doi:10.1095/biolreprod.107.060129)

Lu DP, Chandrakanthan V, Cahana A, Ishii S \& O'Neill C 2004 Trophic signals acting via phosphatidylinositol-3 kinase are required for normal pre-implantation mouse embryo development. Journal of Cell Science 117 1567-1576. (doi:10.1242/jcs.00991)

Maekawa M, Yamamoto T, Kohno M, Takeichi M \& Nishida E 2007 Requirement for ERK MAP kinase in mouse preimplantation development. Development 134 2751-2759. (doi:10.1242/dev.003756)

Masson N, John J \& Lee KA 1993 In vitro phosphorylation studies of a conserved region of the transcription factor ATF1. Nucleic Acids Research 21 4166-4173. (doi:10.1093/nar/21.18.4166REF28=10.1042/ BC20040146) 
Natale DR, Paliga AJ, Beier F, D'Souza SJ \& Watson AJ 2004 p38 MAPK signaling during murine preimplantation development. Developmental Biology 268 76-88. (doi:10.1016/j.ydbio.2003.12.011)

Ohsugi M, Ohsawa T \& Semba R 1993 Similar responses to pharmacological agents of 1,2-OAG-induced compaction-like adhesion of two-cell mouse embryo to physiological compaction. Journal of Experimental Zoology 265 604-608. (doi:10.1002/jez.1402650517)

O'Neill C 1997 Evidence for the requirement of autocrine growth factors for development of mouse preimplantation embryos in vitro. Biology of Reproduction 56 229-237. (doi:10.1095/biolreprod56.1.229)

O'Neill C 2005 The role of paf in embryo physiology. Human Reproduction Update 11 215-228. (doi:10.1093/humupd/dmi003)

O'Neill C 2008a Phosphatidylinositol 3-kinase signaling in mammalian preimplantation embryo development. Reproduction 136 147-156. (doi:10.1530/REP-08-0105)

$\mathbf{O}^{\prime}$ Neill C 2008b The potential roles for embryotrophic ligands in preimplantation embryo development. Human Reproduction Update 14 275-288. (doi:10.1093/humupd/dmn002)

Paliga AJ, Natale DR \& Watson AJ 2005 p38 mitogen-activated protein kinase (MAPK) first regulates filamentous actin at the 8-16-cell stage during preimplantation development. Biology of the Cell 97 629-640. (doi:10.1042/BC20040146)
Parker D, Ferreri K, Nakajima T, LaMorte VJ, Evans R, Koerber SC, Hoeger C \& Montminy MR 1996 Phosphorylation of CREB at Ser-133 induces complex formation with CREB-binding protein via a direct mechanism. Molecular and Cellular Biology 16 694-703.

Wilding M, Torok K \& Whitaker M 1995 Activation-dependent and activation-independent localisation of calmodulin to the mitotic apparatus during the first cell cycle of the Lytechinus pictus embryo. Zygote 3 219-224. (doi:10.1017/S0967199400002616)

Zhang X, Odom DT, Koo S-H, Conkright MD, Canettieri G, Best J, Chen H, Jenner R, Herbolsheimer E, Jacobsen E et al. 2005 Genome-wide analysis of CAMP-response element binding protein occupancy, phosphorylation, and target gene activation in human tissues. PNAS 102 4459-4464. (doi:10.1073/pnas.0501076102)

Received 23 October 2013

First decision 18 November 2013

Revised manuscript received 5 May 2014

Accepted 12 May 2014 